\title{
Effects of Copy Number Variations on Developmental Aspects of Children With Delayed Development
}

\author{
Kee-Boem Park, MD ${ }^{1}$, Kyung Eun Nam, $\mathrm{MD}^{1}$, Ah-Ra Cho, $\mathrm{MD}^{2}$, \\ Woori Jang, $\mathrm{MD}^{3,4}$, Myungshin Kim, MD, $\mathrm{PhD}^{3,4}$, Joo Hyun Park, MD, PhD ${ }^{1}$
}

${ }^{1}$ Department of Rehabilitation Medicine, Seoul St. Mary's Hospital, College of Medicine, The Catholic University of Korea, Seoul; ${ }^{2}$ Department of Rehabilitation Medicine, St. Paul's Hospital, College of Medicine, The Catholic University of Korea, Seoul; ${ }^{3}$ Department of Laboratory Medicine and ${ }^{4}$ Catholic Genetic Laboratory Center, College of Medicine, The Catholic University of Korea, Seoul, Korea

Objective To determine effects of copy number variations (CNV) on developmental aspects of children suspected of having delayed development.

Methods A retrospective chart review was done for 65 children who underwent array-comparative genomic hybridization after visiting physical medicine \& rehabilitation department of outpatient clinic with delayed development as chief complaints. Children were evaluated with Denver Developmental Screening Test II (DDST-II), Sequenced Language Scale for Infants (SELSI), or Preschool Receptive-Expressive Language Scale (PRES). A Mann-Whitney U test was conducted to determine statistical differences of developmental quotient (DQ), receptive language quotient (RLQ), and expressive language quotient (ELQ) between children with $\mathrm{CNV}(\mathrm{CNV}(+)$ group, $\mathrm{n}=16)$ and children without $\mathrm{CNV}(\mathrm{CNV}(-)$ group, $\mathrm{n}=37)$.

Results Of these subjects, the average age was 35.1 months (mean age, $35.1 \pm 24.2$ months). Sixteen (30.2\%) patients had copy number variations. In the $\mathrm{CNV}(+)$ group, 14 children underwent DDST-II. In the CNV(-) group, 29 children underwent DDSTII. Among variables, gross motor scale was significantly ( $\mathrm{p}=0.038)$ lower in the $\mathrm{CNV}(+)$ group compared with the $\mathrm{CNV}(-)$ group. In the $\mathrm{CNV}(+)$ group, 5 children underwent either SELSI or PRES. In the CNV(-) group, 27 children underwent above language assessment examination. Both RLQ and ELQ were similar between the two groups.

Conclusion The gross motor domain in DQ was significantly lower in children with CNV compared to that in children without CNV. This result suggests that additional genetic factors contribute to this variability. Active detection of genomic imbalance could play a vital role when prominent gross motor delay is presented in children with delayed development.

Keywords Developmental disabilities, DNA copy number variations, Array-based comparative genomic hybridization, Motor skills, Hypotonia

Received August 16, 2018; Accepted October 19, 2018

Corresponding author: Joo Hyun Park

Department of Rehabilitation Medicine, Seoul St. Mary's Hospital, 222 Banpo-daero, Seocho-gu, Seoul 06591, Korea. Tel: +82-2-2258-6280, Fax: +82-22258-2825, E-mail: drpjh@catholic.ac.kr

ORCID: Kee-Boem Park (http://orcid.org/0000-0002-9059-058X); Kyung Eun Nam (http://orcid.org/0000-0001-5195-4320); Ah-Ra Cho (http://orcid. org/0000-0003-3533-2243); Woori Jang (http://orcid.org/0000-0001-8376-0133); Myungshin Kim (http://orcid.org/0000-0001-8632-0168); Joo Hyun Park (http://orcid.org/0000-0001-9257-8704).

(a) This is an open-access article distributed under the terms of the Creative Commons Attribution Non-Commercial License (http://creativecommons.org/ licenses/by-nc/4.0) which permits unrestricted noncommercial use, distribution, and reproduction in any medium, provided the original work is properly cited. Copyright ( 2019 by Korean Academy of Rehabilitation Medicine 


\section{INTRODUCTION}

Over the recent years, our knowledge of copy number variation (CNV) in the human genome has evolved rapidly. Applications of increasingly higher resolution array based techniques, particularly microarray-based comparative genomic hybridization (array-CGH), have been proven invaluable in discovering disease-causing $\mathrm{CNV}$ in a wide variety of disorders ranging from pediatric diseases (neurological and congenital birth defects) to adult-onset neuropsychiatric diseases such as Alzheimer disease [1-3].

CNVs represent the imbalance of genomic sequence compared with the reference genome. They may range in size from kilobases (kb) to megabases (Mb). CNV can occur due to structural changes within the genome, including duplications, deletions, insertions, and translocations. It can lead to either an increase or decrease of genomic segments [4-6].

CNV can be expressed in disease phenotype by various mechanisms. Alteration of coding regions in copy number of dosage-sensitive genes plays a primary role in pathogenesis $[1,7]$. Disruption of regulatory elements on non-coding region may also play some crucial roles [8]. Establishing pathogenicity of $\mathrm{CNV}$ is the major challenge in the interpretation of array results due to rarity of many individual CNV, difficulty of identifying exact dosagesensitive genes, and considerable variations in expressivity $[1,9]$. The clinical significance of a CNV is usually determined by its mode of inheritance, size, type (deletion and duplication), gene content, and comparison with CNV databases [10-12].

Developmental delay refers to children who significantly lag in developmental features and skills in motor, language, social, and cognitive developmental domains at expected age [13]. The cause of developmental disabilities is diverse and often unknown. However, environmental factors, biological factors, and complications of pregnancy have been suggested as possible causes [14].

Early detection of pathogenic CNV plays a crucial role as it allows referrals for appropriate treatment, improves prognosis, and enables better genetic counseling for the family. Consequently, effort has been made to identify clinically relevant $\mathrm{CNV}$ that can facilitate the characterization of phenotypic consequences [7,14].

Although array-CGH has been adopted as a first-tier clinical diagnostic test in individuals with developmental disabilities, especially in economically developed countries [11], applying array-CGH to every individual presented with delayed development as a routine study is impractical due to limited accessibility to facilities offering comprehensive diagnostic testing and its high cost $[14,15]$.

Patients with CNV may present with varying clinical features. It is highly probable that CNV plays a role in the manifestation of symptoms for those who have delayed development [1]. To the best of our knowledge, studies utilizing quantified measurements for development domains of children with delayed development have not been reported yet. Therefore, the objective of this study was to determine effects of CNV on developmental aspects of children suspected of having delayed development. Clinical development aspect of children suspected of having delayed development was compared between those who had CNV and those who did not have CNV.

\section{MATERIALS AND METHODS}

\section{Subjects}

A retrospective chart review was done for 65 children who underwent array-CGH after visiting physical medicine \& rehabilitation department of outpatient clinic with delayed development as chief complaints from January 2016 to November 2017. More than one test of Sequenced Language Scale for Infants (SELSI), Preschool ReceptiveExpressive Language Scale (PRES), and Denver Developmental Screening Test II (DDST-II) was conducted for these children.

Inclusion criteria were: (1) interpreted as 'suspect' in DDST-II defined as those who scored two or more cautions and/or one or more delays [16], and (2) at least one of receptive or expressive language domains in SELSI or PRES fell below 2 standard deviations compared to children of the same age.

\section{Methods}

This study was carried out through retrospective chart review. It was approved by Institutional Review Board of Seoul St. Mary's Hospital (No. KC18RCSI0483). The requirement for informed consent from individual patients was omitted because of the retrospective design of this study. Thorough chart review was performed to distin- 
guish factors that might affect general development of the patient, including prenatal, natal, postnatal risk factors and brain magnetic resonance imaging interpretation. Prenatal factors consisted of diagnosis of intrauterine growth restriction, eclampsia, hydramnios or oligoamnios, threatened abortion, and placenta previa. Natal factors included history of asphyxia, jaundice, meconium staining, premature birth, and low birth weight. Postnatal factors included neonatal convulsion and feeding difficulty.

Children were evaluated by DDST-II, SELSI, or PRES. DDST was first introduced in 1967 and revised in 1992. It targets infants and children aged between 0 and 6 years old. It is one of the most widely utilized tools for screening children with delayed development. DDST-II is assessed in four developmental domains: gross motor, fine motor-adaptive, language, and social-personal domains [17]. Although DDST-II is not intended to yield a developmental quotient (DQ) originally, recent study has suggested that DQ from DDST-II may correlate well with diagnosis of several pediatric developmental and behavioral disorders [18]. Thus, DQ has been utilized in number of studies [19-22]. In addition, several studies have compared DDST-II with various diagnostic tools for developmental delay, revealing some correlations. In one study, mental developmental index from the Bayley Scales of Infant Development II was significantly correlated with all four domains of DDST-II and psychomotor development index was significantly related with gross motor, fine motor-adaptive, and social-personal domains of DDST-II [23]. Therefore, in the current study, DQ was utilized to assess different domains of development between the two groups. Functional age of the patient was measured with the four developmental domains of DDST-II. DQ was calculated by dividing the developmental age by chronologic age. It is expressed in percentage [19]. For language assessment, we used SELSI and PRES depending on patient's age. Receptive language quotient (RLQ) and expressive language quotient (ELQ) were calculated by dividing receptive score and language score by chronologic age, respectively. They are expressed in percentage [24]. The first test from the date of referral was utilized if the patient was evaluated with serial tests.

Array-CGH analysis was performed with SurePrint G3 Human CGH Microarray $8 \times 60 \mathrm{~K}$ kit (Agilent Technologies, Santa Clara, CA, USA) which consisted of 62,976 oligonucleotide probes spaced at $41 \mathrm{kbp}$ intervals (median probe spacing) according to the manufacturer's protocol. CNVs were detected using Aberration Detection Method 2 (ADM-2) algorithm. Genomic positions were defined according to human reference genome hg19/GRCh37.

\section{Statistics}

The statistical software SPSS version 24.0 for Windows (IBM, Armonk, NY, USA) was utilized for data processing. A Mann-Whitney U test was conducted to determine statistical differences of DQ, RLQ, and ELQ between children with $\mathrm{CNV}(\mathrm{CNV}(+)$ group, $\mathrm{n}=16)$ and children without $\mathrm{CNV}(\mathrm{CNV}(-)$ group, $\mathrm{n}=37)$. Statistical significance was set at $\mathrm{p}<0.05$.

Table 1. General demographics of subjects included for this study

\begin{tabular}{lccc}
\hline \multicolumn{1}{c}{ Variable } & $\begin{array}{c}\text { Patients with CNV } \\
(\mathbf{n}=\mathbf{1 6})\end{array}$ & $\begin{array}{c}\text { Patients without CNV } \\
(\mathbf{n}=\mathbf{3 7})\end{array}$ & p-value \\
\hline Age (mo) & $27.6 \pm 21.6$ & $39.4 \pm 24.3$ & 0.072 \\
Gender, male (\%) & 56.25 & 62.16 & 0.741 \\
\hline Intrauterine periods (wk) & $38.18 \pm 1.53$ & $37.47 \pm 3.67$ & 0.915 \\
\hline Birth weight (g) & $2,843 \pm 58.64$ & $2,774 \pm 75.05$ & 0.892 \\
\hline Prenatal risk factors (\%) & 18.8 & 16.2 & 0.831 \\
\hline Natal risk factors (\%) & 43.8 & 35.1 & 0.564 \\
\hline Postnatal risk factors (\%) & 18.8 & 10.8 & 0.464 \\
\hline Abnormal brain MRI (\%) & 31.3 & 24.3 & 0.551 \\
\hline
\end{tabular}

Values are presented as mean \pm standard deviation.

$\mathrm{CNV}$, copy number variation; MRI, magnetic resonance imaging. 


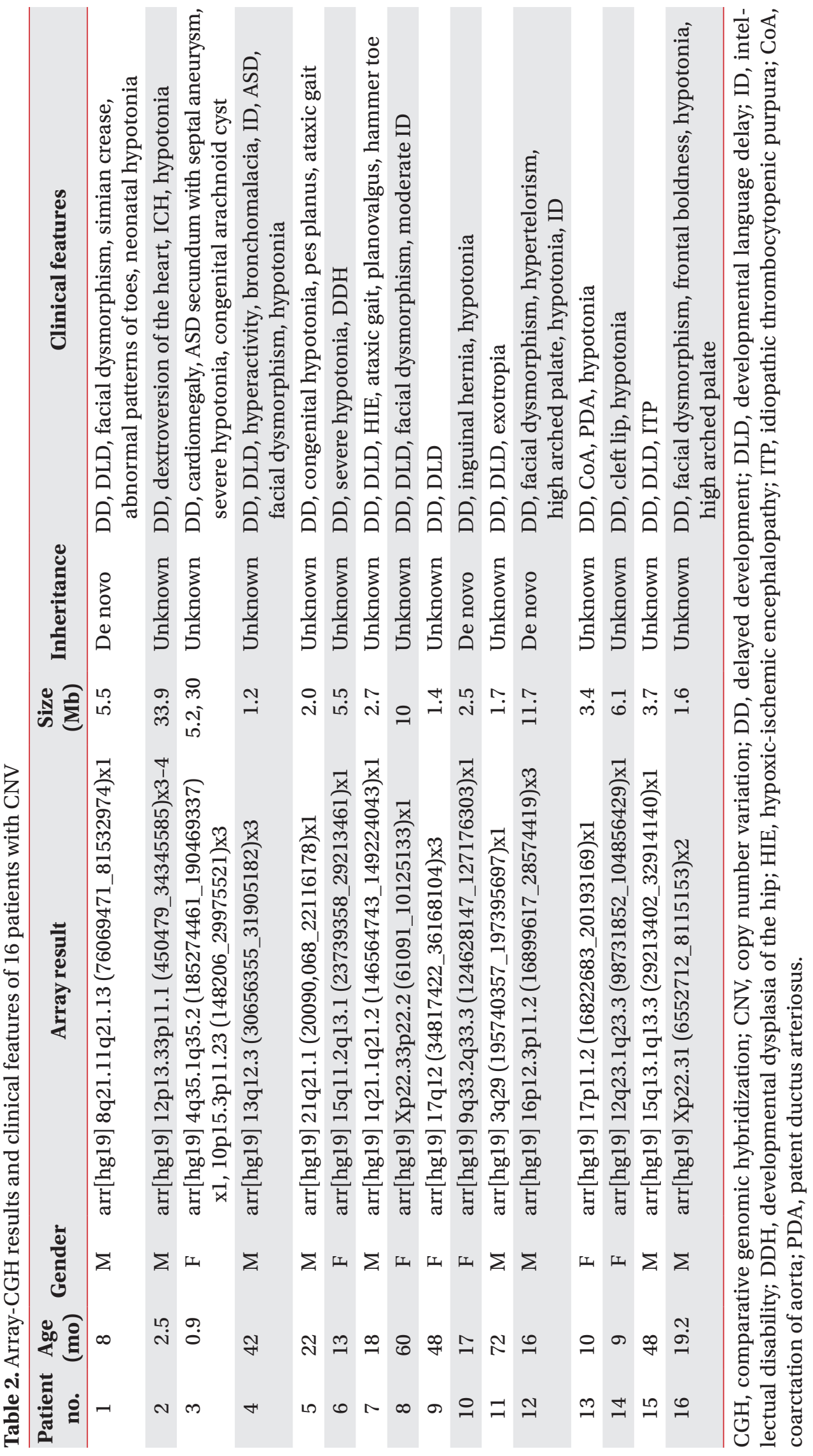




\section{RESULTS}

\section{General demographics}

Of 65 children who underwent array-CGH after visiting physical medicine \& rehabilitation department outpatient clinic with delayed development as chief complaints, 53 patients met the inclusion criteria. Fortythree patients undertook DDST-II and 32 patients took at least one of SELSI or PRES. Twenty-three patients received both DDST-II and at least one of SELSI or PRES. Nine patients were evaluated only with SELSI/PRES. They were not evaluated with DDST-II because they were either more than 6 years old or had prior test results from different clinics. Average age of all patients was 35.1 months (mean age, 35.1 \pm 24.2 months). There were 32 $(60.4 \%)$ boys. The $\mathrm{CNV}(+)$ group consisted of 16 patients (9 males) aged between 1 month and 72 months (mean age, 27.6 \pm 21.6 months). The $\mathrm{CNV}(-)$ group consisted of 37 patients ( 23 males) aged between 1.5 months and 84 months (mean age, $39.4 \pm 24.3$ months). There was no significant difference in age or gender between the two groups (Table 1).

\section{Perinatal history}

Prenatal problems were observed in 3 patients (18.8\%) in the $\mathrm{CNV}(+)$ group and 6 patients $(16.2 \%)$ in the $\mathrm{CNV}(-)$ group. Natal risk factors were observed in 7 patients (43.8\%) in the $\mathrm{CNV}(+)$ group and 13 patients $(35.1 \%)$ in the $\mathrm{CNV}(-)$ group. Postnatal problems were presented in 3 patients $(18.8 \%)$ in the $\mathrm{CNV}(+)$ group and 4 patients $(10.8 \%)$ in the $\mathrm{CNV}(-)$ group. Average gestational age was 38.18 weeks in the $\mathrm{CNV}(+)$ group and 37.48 weeks in the $\mathrm{CNV}(-)$ group. Average birth weights were 2,843 $\mathrm{g}$ and 2,774 $\mathrm{g}$ in $\mathrm{CNV}(+)$ and $\mathrm{CNV}(-)$ groups, respectively. Eleven patients in the $\mathrm{CNV}(+)$ group and 26 patients in the $\mathrm{CNV}(-)$ group had brain magnetic resonance imaging records. Abnormal brain image findings were presented in 5 patients $(31.3 \%)$ in the $\mathrm{CNV}(+)$ group and 9 patients (24.3\%) in the CNV(-) group. There were no significant differences in prenatal problems, natal risk factors, postnatal problems, gestational age, or abnormal findings in brain images between the two groups (Table 1).

\section{Clinical presentations}

Clinical features of the 16 children with copy number variations are shown in Table 2 . Amongst these 16 children in the $\mathrm{CNV}(+)$ group, 11 children $(68.8 \%)$ presented with hypotonia. Amongst 37 children in the CNV(-) group, 10 children $(27.0 \%)$ presented with hypotonia at the time of the first visit. Of these 21 patients who presented with hypotonia, $11(52.4 \%)$ were diagnosed with copy number variations. Of the $16 \mathrm{CNV}(+)$ patients, average size of CNV was $8.01 \mathrm{Mb}$ (mean, $8.01 \pm 10.80 \mathrm{Mb}$ ).

\section{Comparison of DDST-II between CNV(+) and CNV(-) groups}

In the $\mathrm{CNV}(+)$ group, 14 children underwent DDSTII. In the CNV(-) group, 29 children underwent DDST-

Table 3. Comparison between two patient groups classified by copy number variation

\begin{tabular}{|lcccc}
\hline & Total & Patients with CNV & Patients without CNV & p-value \\
\hline DDST-II (developmental quotient) & & & & \\
\hline Personal-social & $63.6 \pm 20.4$ & $67.5 \pm 17.4$ & $61.7 \pm 21.7$ & 0.468 \\
\hline Fine motor-adaptive & $71.1 \pm 19.9$ & $69.4 \pm 21.1$ & $71.9 \pm 19.7$ & 0.338 \\
\hline Gross motor & $64.0 \pm 19.1$ & $57.7 \pm 13.2$ & $67.1 \pm 21.0$ & $0.038^{*}$ \\
\hline Language & $57.1 \pm 22.1$ & $65.9 \pm 25.0$ & $52.9 \pm 19.7$ & 0.140 \\
\hline Number of patients & 43 & 14 & 29 & 0.938 \\
\hline SELSI or PRES & & & & 0.243 \\
\hline Receptive language quotient & $49.6 \pm 20.6$ & $47.8 \pm 16.9$ & $49.9 \pm 21.4$ & \\
\hline Expressive language quotient & $47.9 \pm 17.2$ & $51.9 \pm 20.6$ & $47.1 \pm 16.9$ & 27 \\
\hline Number of patients & 32 & 5 & & \\
\hline
\end{tabular}

Values are presented as mean \pm standard deviation.

DDST-II, Denver Developmental Screening Test II; SELSI, Sequenced Language Scale for Infants; PRES, Preschool Receptive-Expressive Language Scale.

${ }^{*} \mathrm{p}<0.05$. 
II. Among variables, gross motor scale was significantly $(\mathrm{p}=0.038)$ lower in the $\mathrm{CNV}(+)$ group than that in the $\mathrm{CNV}(-)$ group. There was no significant difference in personal-social, fine motor-adaptive, or language domain between the two groups (Table 3).

\section{Comparison of SELSI or PRES between CNV(+) and CNV(-) groups}

In the $\mathrm{CNV}(+)$ group, 5 children underwent either SELSI or PRES. In the CNV(-) group, 27 children underwent the above language assessment examination. Both receptive and expressive language scores were similar between the two groups.

\section{DISCUSSION}

Diagnostic yield of genetic testing of patients with unexplained developmental delay, autism spectrum disorders, or multiple congenital anomalies is generally thought to be $15 \%-20 \%$ [11]. Cooper et al. [1] have calculated that $25.7 \%$ of individuals with developmental delay or intellectual disability have $\mathrm{CNV}>400 \mathrm{~kb}$ in length and estimated that $14.2 \%$ are due to these large CNVs. In our study, 16 of $53(30.2 \%)$ yielded positive results for CNV, showing slightly higher yield.

CNV can be inherited or sporadic. Rare and de novo CNVs are thought to play more prominent roles in neurologic disorders $[7,9,25,26]$. Studies have suggested that vast majority of benign CNVs are inherited and most of inherited CNVs are lesser than $500 \mathrm{~kb}$ in size [27]. Larger CNVs have higher probability than smaller CNVs to cause disease. They are associated with more severe developmental phenotypes [1,28]. In our study, among $16 \mathrm{CNV}$ (+) patients, three patients were found to have de novo CNVs. However, whether CNVs were inherited were unknown for most patients since few patients underwent parental study. Average size of CNVs was $8.01 \mathrm{Mb}$ (mean, $8.01 \pm 10.80 \mathrm{Mb}$ ). All patients had CNV size greater than $1 \mathrm{Mb}$ which increased the likelihood of pathogenicity cause by CNV and decreased the likelihood of false positive rate.

CNV enrichment is known to differ depending on clinical phenotype. Patients with cardiac congenital anomalies and craniofacial abnormalities are known to have the most significant CNV burden [1]. In our study, significantly more patients in the $\mathrm{CNV}(+)$ group presented with either cardiac abnormality or facial dysmorphism compared to those in the $\mathrm{CNV}(-)$ group (50.0\% vs. $13.5 \%$, $\mathrm{p}=0.0434)$. Many CNVs of specific genes such as $17 \mathrm{q} 21.31$ microdeletion, $2 \mathrm{q} 11.2$ duplication, $2 \mathrm{q} 13$ deletion, and 1q21.1 deletions/duplications [7,29] are associated with hypotonia amongst many clinical phenotypes. In 17q21.31 microdeletion, two candidate genes (CRHR1 and MAPT) have been proposed to be pathogenic [7]. In our study, it was apparent that more patients in the $\mathrm{CNV}(+)$ group had hypotonia than those in the $\mathrm{CNV}(-)$ group ( $68.8 \%$ vs. $28.3 \%, p=0.012$ ). Similar to previous studies, patients in the $\mathrm{CNV}(+)$ group manifested with varying clinical features involving variable genes. However, no significant study has compared major genetic burden utilizing quantitative measurements of developmental domains. The current study revealed significant difference in gross motor domain in DDST-II between patients with or without CNV. This result suggests that gross motor skills might be affected the most severely when patients with delayed development show CNV, although CNV may present diverse clinical features.

Gialluisi et al. [30] have investigated effects of CNV on reading and language performance by measuring relationship between genomic burden and the first principal component score derived from reading and language traits. Their results suggested that CNV did not contribute a substantial proportion to variance in language and reading performance. In our study, both receptive and expressive language scores from SELSI/PRES and language domain from DDST-II were similar between the two groups.

High resolution array-CGH provides a way for detecting microdeletions and microduplications. It has replaced Gband karyotype analysis or fluorescent in situ hybridization. Array-CGH has effectively increased diagnostic yield in genomic disorders, leading to its application as the first tier of testing by many centers around the world for individuals with neurodevelopmental disorders and congenital abnormalities $[11,31]$. The benefit of early detection of specific genetic diagnosis in congenital disorders is paramount as it allows higher rate of recommendation for clinical action, especially for inborn errors of metabolism [14,32], surveillance for potential future involvement of other pathogenic conditions, and appropriate recurrence risk counseling for the family $[1,11]$. However, when presented with borderline symptoms of delayed 
development or in places with scarce resources, it is impractical to apply array-CGH to every individual [15]. Our study could help us prioritize and decide whether to apply array-CGH to patients suspected with delayed development. Our results suggest that active detection of patients with prominent gross motor skill decline with hypotonia may increase the likelihood of CNV detection.

Our study had a few limitations. First, the sample size was limited to 53 patients. Especially, the number of patients with CNV who took SELSI/PRES was only 5. Second, our study incorporated developmental quotient in DDST-II. The use of psychometric characteristic scale is questioned. Future studies incorporating different diagnostic tools such as composite scales of the Bayley Scales of Infant Development II may yield additional results. Third, patients were selected only at a single tertiary medical institution which might contain selection bias. Fourth, patients selected were diverse in age, especially for the $\mathrm{CNV}(-)$ group. In addition, average age of selected patients was generally very young. Consequently, delay in motor function might be the most noticeable feature compared to cognitive or language domain. Grouping or narrowing down of age group with larger population may yield additional results. On the other hand, studying a younger age group may provide more valuable information as it is related to early detection and intervention. Lastly, detecting CNV through microarray studies does not completely exclude genetic causality since singlenucleotide variations and small insertion/deletions not detectable by array-CGH might have been the origin of pathogenicity. Additional next-generation sequencing techniques such as whole genome sequencing may increase the diagnostic yield. However, clinical implementation of whole genome sequencing remains limited, although it has been gaining popularity [15,33]. Similar experiment utilizing whole genome sequencing may yield additional results. Therefore, future large-scale prospective studies are warranted.

In conclusion, the role of CNV in human disease has become increasingly revealed as a result of advanced tools for genome analysis. In our study, the gross motor domain in DQ was significantly lower in children with CNV compared to that in children without CNV. This result suggests that additional genetic factors may contribute to this variability. Active detection of genomic imbalance could play some vital roles when children with delayed development show prominent gross motor delay.

\section{CONFLICT OF INTEREST}

No potential conflict of interest relevant to this article was reported.

\section{ACKNOWLEDGMENTS}

This study was supported by the National Research Foundation of Korea (NRF) grant funded by the Korean Government (No. 2015S1A5A2A03047970).

\section{AUTHOR CONTRIBUTION}

Conceptualization: Park KB, Cho AR, Park JH. Methodology: Park KB, Cho AR, Jang WR, Kim MS, Park JH. Formal analysis: Park KB, Park JH. Funding acquisition: Park JH. Project administration: Park JH. Visualization: Park KB, Nam KE, Park JH. Writing - original draft: Park KB. Writing - review and editing: Park KB, Nam KE, Jang WR, Kim MS, Park JH. Approval of final manuscript: all authors.

\section{REFERENCES}

1. Cooper GM, Coe BP, Girirajan S, Rosenfeld JA, Vu TH, Baker C, et al. A copy number variation morbidity map of developmental delay. Nat Genet 2011;43:83846.

2. Greenway SC, Pereira AC, Lin JC, DePalma SR, Israel SJ, Mesquita SM, et al. De novo copy number variants identify new genes and loci in isolated sporadic tetralogy of Fallot. Nat Genet 2009;41:931-5.

3. Mefford HC, Clauin S, Sharp AJ, Moller RS, Ullmann $\mathrm{R}$, Kapur R, et al. Recurrent reciprocal genomic rearrangements of $17 \mathrm{q} 12$ are associated with renal disease, diabetes, and epilepsy. Am J Hum Genet 2007; 81:1057-69.

4. Iafrate AJ, Feuk L, Rivera MN, Listewnik ML, Donahoe PK, Qi Y, et al. Detection of large-scale variation in the human genome. Nat Genet 2004;36:949-51.

5. Redon R, Ishikawa S, Fitch KR, Feuk L, Perry GH, Andrews $\mathrm{TD}$, et al. Global variation in copy number in the human genome. Nature 2006;444:444-54.

6. Sebat J, Lakshmi B, Troge J, Alexander J, Young J, Lun- 
din P, et al. Large-scale copy number polymorphism in the human genome. Science 2004;305:525-8.

7. Stankiewicz P, Lupski JR. Structural variation in the human genome and its role in disease. Annu Rev Med 2010;61:437-55.

8. Zhang F, Lupski JR. Non-coding genetic variants in human disease. Hum Mol Genet 2015;24:R102-10.

9. Watson CT, Marques-Bonet T, Sharp AJ, Mefford HC. The genetics of microdeletion and microduplication syndromes: an update. Annu Rev Genomics Hum Genet 2014;15:215-44.

10. Martin CL, Kirkpatrick BE, Ledbetter DH. Copy number variants, aneuploidies, and human disease. Clin Perinatol 2015;42:227-42.

11. Miller DT, Adam MP, Aradhya S, Biesecker LG, Brothman AR, Carter NP, et al. Consensus statement: chromosomal microarray is a first-tier clinical diagnostic test for individuals with developmental disabilities or congenital anomalies. Am J Hum Genet 2010;86:74964.

12. Sagoo GS, Butterworth AS, Sanderson S, Shaw-Smith C, Higgins JP, Burton H. Array CGH in patients with learning disability (mental retardation) and congenital anomalies: updated systematic review and metaanalysis of 19 studies and 13,926 subjects. Genet Med 2009;11:139-46.

13. Shevell M. Global developmental delay and mental retardation or intellectual disability: conceptualization, evaluation, and etiology. Pediatr Clin North Am 2008;55:1071-84.

14. van Karnebeek CD, Stockler S. Treatable inborn errors of metabolism causing intellectual disability: a systematic literature review. Mol Genet Metab 2012;105:368-81.

15. Hehir-Kwa JY, Pfundt R, Veltman JA. Exome sequencing and whole genome sequencing for the detection of copy number variation. Expert Rev Mol Diagn 2015;15:1023-32.

16. Frankenburg WK. Denver II: training manual. 2nd ed. Denver: Denver Developmental Materials Inc.; 1992.

17. Frankenburg WK, Dodds J, Archer P, Shapiro H, Bresnick B. The Denver II: a major revision and restandardization of the Denver Developmental Screening Test. Pediatrics 1992;89:91-7.

18. Sularyo T, Endyarni B, Lestari T, Tamin TZ, Gitayanti G. Role of Denver II and Development Quotients in the management of several pediatric developmental and behavioral disorders. Paediatr Indones 2012;52:51-6.

19. Charan GS, Vagha J. Study of perinatal factors in children with developmental delay. Int J Contemp Pediatr 2017;4:182-90.

20. Nguefack S, Kamga KK, Moifo B, Chiabi A, Mah E, Mbonda E. Causes of developmental delay in children of 5 to 72 months old at the child neurology unit of Yaounde Gynaeco-Obstetric and Paediatric Hospital (Cameroon). Open J Pediatr 2013;3:279-85.

21. Sohn YB, Cho SY, Lee J, Kwun Y, Huh R, Jin DK. Safety and efficacy of enzyme replacement therapy with idursulfase beta in children aged younger than 6 years with Hunter syndrome. Mol Genet Metab 2015;114:156-60.

22. Tiwari K, Goyal S, Malvia S, Sanadhya A, Suman RL, Jain R. Impact of malnutrition on head size and development quotient. Int J Res Med Sci 2017;5:3003-6.

23. Shin H, Kwon B, Lim S. Validity of Korean version of Denver II in screening children with developmental risk. Korean J Child Health Nurs 2005;11:316-21.

24. Kim SW, Jeon HR, Park EJ, Chung HJ, Song JE. The differences in clinical aspect between specific language impairment and global developmental delay. Ann Rehabil Med 2014;38:752-8.

25. Kurotaki N, Shen JJ, Touyama M, Kondoh T, Visser R, Ozaki T, et al. Phenotypic consequences of genetic variation at hemizygous alleles: Sotos syndrome is a contiguous gene syndrome incorporating coagulation factor twelve (FXII) deficiency. Genet Med 2005;7:47983.

26. Lupski JR. Structural variation in the human genome. N Engl J Med 2007;356:1169-71.

27. McCarroll SA, Kuruvilla FG, Korn JM, Cawley S, Nemesh J, Wysoker A, et al. Integrated detection and population-genetic analysis of SNPs and copy number variation. Nat Genet 2008;40:1166-74.

28. de Vries BB, Pfundt R, Leisink M, Koolen DA, Vissers LE, Janssen IM, et al. Diagnostic genome profiling in mental retardation. Am J Hum Genet 2005;77:606-16.

29. Bernier R, Steinman KJ, Reilly B, Wallace AS, Sherr EH, Pojman N, et al. Clinical phenotype of the recurrent 1q21.1 copy-number variant. Genet Med 2016;18:3419.

30. Gialluisi A, Visconti A, Willcutt EG, Smith SD, Pennington BF, Falchi M, et al. Investigating the effects of 
copy number variants on reading and language performance. J Neurodev Disord 2016;8:17.

31. Coughlin CR 2nd, Scharer GH, Shaikh TH. Clinical impact of copy number variation analysis using highresolution microarray technologies: advantages, limitations and concerns. Genome Med 2012;4:80.

32. Coulter ME, Miller DT, Harris DJ, Hawley P, Picker
J, Roberts AE, et al. Chromosomal microarray testing influences medical management. Genet Med 2011;13:770-6.

33. Gilissen C, Hehir-Kwa JY, Thung DT, van de Vorst M, van Bon BW, Willemsen MH, et al. Genome sequencing identifies major causes of severe intellectual disability. Nature 2014;511:344-7. 